\title{
What to Expect After Sendai: Looking Forward to More Effective Disaster Risk Reduction
}

\author{
Sálvano Briceño ${ }^{1,2,3}$
}

Published online: 10 June 2015

(c) The Author(s) 2015. This article is published with open access at Springerlink.com

The Sendai Framework represents the most complete international policy instrument on disaster risk reduction to date. It complements and updates the Hyogo Framework and provides comprehensive guidance to governments, but also to other organizations, NGOs, the private sector, local authorities, and academic institutions in their efforts to reduce risk related with natural hazards.

Nevertheless, policy guidelines are only that, guidelines for political and community leaders to use in their work of guiding and facilitating actual work at various levels, in various sectors, and with multiple stakeholders. It is leadership and management capacities that are required for actually effecting change in any society, be it at the local, national, or even international level.

Internationally agreed guidelines are applied in different ways and with different approaches by individuals and organizations around the world. The differences are mainly due to the availability, or not, of aware and competent leaders and managers whose teamwork can introduce changes in any given community to address risk reduction in an effective manner. Therefore, institutions responsible for policy and education on disaster risk reduction-in particular, governments, NGOs, international organizations, and academic institutions-need to focus on

Sálvano Briceño

salvanob@gmail.com

1 Science Committee, Integrated Research on Disaster Risk (IRDR) Program of the International Council for Science (ICSU), Paris, France

2 International Social Science Council (ISSC), Paris, France

3 United Nations International Strategy for Disaster Reduction (UNISDR), Geneva, Switzerland identifying and supporting existing competent leaders and managers and using their work as a model to promote elsewhere, in locations where such capacities are still not fully developed.

Rather than address the many valuable recommendations the Sendai Framework contains, I wish to focus in this brief commentary on the framework's shortcomings and, in particular, on the most urgent tasks that need to be undertaken. Among the shortcomings, three main issues appear to be missing: prioritization in the implementation of the recommended actions; quantified targets; and a plan for the implementation of the framework.

\section{Prioritization}

Identifying priorities is a most urgent task. The Sendai Framework, as the Hyogo Framework before it, presents a long list of actions to be carried out by governments, who in situations of shortage of resources have great difficulty implementing these actions. In these situations selective action becomes a necessity, either by picking and choosing as if actions proposed were of equal relevance or by delaying implementation given the magnitude of the task. A sense of what is most urgent and an indication of gradual steps toward full implementation would be, in my view, a necessary complement to the Sendai Framework.

This would greatly facilitate government action, not only in attempting to reduce risk of disasters but also, and most importantly, in achieving orderly and effective implementation of the sustainable development goals (SDG), as well as the new goals expected to be adopted at the upcoming climate change (CC) agreement. In both cases, governments must begin by putting in place risk management strategies in 
order to undertake and ensure effective adaptation and mitigation policies. Unattended risk will make the objectives of the CC agreement and the SDG more difficult and expensive to achieve. Raising awareness on the need for prioritization should become a key goal for the Third International Conference on Financing for Development (Addis Abeba 13-16 July 2015).

\section{Quantified Targets}

Quantifying all targets would have been a difficult task to negotiate among countries with very diverse situations and resources. However, a limited number of targets could have benefited from specific quantified aims, setting the path to address more of them gradually in the coming years.

Work in this direction would be facilitated by a more intensive utilization of findings in the Global Assessment Report on Disaster Risk Reduction (GAR) 2015. This and previous GARs could have been better utilized in the preparation of a draft framework to be discussed with governments, involving experts more actively in discussions with government officials to explain better the relevance of the recommendations made by the GAR and secure a more concrete framework.

\section{Implementation}

The Sendai Framework provides good recommendations for follow-up actions and as a whole represents a major step in the right direction. Most participants were undoubtedly influenced by the discussions and information exchanged and, more importantly, by the contacts made and networks developed. They will multiply efforts towards implementing policies and measures to reduce the risk of disasters in their many locations and functions. However, because of the major shift still required in understanding that managing risk is mostly about reducing vulnerability and not just understanding hazards and emergencies, many such efforts will still remain scattered and have insufficient impact.

Therefore, a major initiative is still needed to rally relevant stakeholders behind a common strategy that addresses the obstacles to understanding risk and implementing risk management programs in places still at risk. At the international level, UNISDR is best positioned to undertake the leadership needed to rally, in particular, international organizations to promote together these goals and facilitate their achievement. This common strategic perspective is especially critical for the Financing for Development, SDG, and climate change negotiations later in 2015. Disaster risk reduction should be an essential component of these discussions, but will still be treated as one more of many objectives unless disaster risk management and reduction efforts acquire a sense of priority and relevance with regard to other goals.

The challenge in all these development tasks (health, nutrition, agriculture, industry, infrastructure, urban management, environment, energy, tourism, and so on), is not so much to insist on the importance of disaster risk reduction as a separate and overriding task. Rather the need is to address disaster risk reduction first before undertaking the other tasks. All other development efforts usually suffer from insufficient risk management and all of them need to integrate risk management approaches into their own implementation design lest their gains become undercut episodically by disasters.

Current knowledge and experience on disaster risk reduction is sufficient to address the challenges facing those nations and communities that have not as yet fully addressed risk reduction. It is not knowledge but rather leadership to use the knowledge that is in question. Therefore, a most urgent task would be to facilitate promotion and dissemination of existing knowledge, in particular the Sendai Framework for Disaster Risk Reduction 2015-2030, to leaders and officials in those nations and communities still lacking appropriate risk management strategies, policies, and programs.

The Sendai Framework extensively addresses the need for financial resources, an issue we can easily agree on but this agreement fails to identify the lack of appropriate understanding of risk management as a top priority. Understanding this priority, more than financial resources, requires a shift in understanding risk and developing risk management capacities, and moving beyond the traditional and still high priority emergency management task. The Sendai Framework adds an unnecessary focus on emergency management, a different task that requires in-depth, but separate, attention from risk management. In this respect, the Sendai Framework goes backwards with regard to the Hyogo Framework and the current evolution on disaster risk reduction.

If substantive resources were allocated with the current understanding of risk, that is, as a hazard or emergency more than a vulnerability issue, these resources would go to the wrong purposes. Investing in shifting mentalities, attitudes, and behavior, utilizing the right leadership, and putting in place risk management capacities seem the real priorities and not so expensive tasks. This would, however, require a common approach in the international system with a joint plan by relevant stakeholders-governmental and nongovernmental, public and private-and in particular with substantive involvement of scientific and academic experts, working together to communicate the key messages still needed to shift paradigm and practice. 
The work of UNISDR and other relevant international organizations (governmental and nongovernmental), building on the experience of nations and communities that have been able to reduce risk and losses related to natural hazards, has been most useful so far in propagating available knowledge around the world. However, uniting forces and building a strong team to convey a set of key messages to leaders in places still at risk can make the difference in effectively reducing risk and poverty, which are both required to secure sustainable development on the planet. This would be in keeping with the overarching "Delivering as One" function of the United Nations System. The challenging tasks of building such a global team effort would require a separate article, which would be meaningless without the relevant leadership interested in carrying it out.

Open Access This article is distributed under the terms of the Creative Commons Attribution 4.0 International License (http:// creativecommons.org/licenses/by/4.0/), which permits unrestricted use, distribution, and reproduction in any medium, provided you give appropriate credit to the original author(s) and the source, provide a link to the Creative Commons license, and indicate if changes were made. 